\title{
The Intellectual Influence of Economic Journals: Quality versus Quantity
}

\author{
László Á. Kóczy · Alexandru Nichifor
}

Received: date / Accepted: date

\begin{abstract}
The evaluation of scientific output has a key role in the allocation of research funds and academic positions. Decisions are often based on quality indicators for academic journals and over the years a handful of scoring methods have been proposed for this purpose. Discussing the most prominent methods (de facto standards) we show that they do not distinguish quality from quantity at article level. The systematic bias we find is analytically tractable and implies that the methods are manipulable. We introduce modified methods that correct for this bias, and use them to provide rankings of economic journals. Our methodology is transparent; our results are replicable.
\end{abstract}

Keywords Modified invariant method - Invariance to article-splitting . Influence of economic journals · Impact factor · LP method · Invariant method

PACS JEL Classification A1 · C8 · D72 · Y1

\footnotetext{
An earlier version of this paper circulated under the title "Intellectual Influence: Quality versus Quantity". We thank Çă̆atay Kayı, András Keszthelyi, Bettina Klaus, Scott Kominers, Itay Fainmesser, Martin Strobel, William Thomson, an associate editor, and an anonymous referee, for helpful discussions and comments. Kóczy thanks funding from OTKA (NF72610), the E.C. (PERG-GA-2008-230879) and the HAS (LP-004/2010). Nichifor thanks funding from NWO (VIDI-452-06-013), METEOR, and SIRE.

L. Á. Kóczy

Centre for Economic and Regional Sciences, Hungarian Academy of Sciences, Budaörsi út 45, H-1112 Budapest and Óbuda University, Budapest.

E-mail: koczy@iehas.hu

A. Nichifor

University of St Andrews, School of Economics and Finance, Castlecliffe, The Scores, , KY16

9AL, UK.

E-mail: alexandru.nichifor@st-andrews.ac.uk
} 


\section{Introduction}

The last decades saw an explosion in the number of academic journals. Researchers find it more and more difficult to keep up with the growing literature even in narrow fields. Libraries face higher subscription fees and must allocate budgets in an efficient way. Promotion decisions are often taken based on researchers' publications. National organizations for scientific research steer the course of science by funding proposals based on their potential and on the publication record of the applicants. However, the quality of the publications, approximated by the containing journals' quality indicator, is becoming increasingly difficult to evaluate and compare. Consequently, there is a growing interest in finding measures, both cardinal and ordinal, that would allow for an objective assessment. To this end, various scoring methods and ranking rules have been devised. The former capture the cardinal aspect, by giving scores to each journal, and the latter capture the ordinal aspect, by establishing an order of preference among the journals.

Loosely speaking, a scoring (or ranking) problem can be thought of as a social choice problem where a social welfare function is used to obtain total preorders on the set of alternatives, with the additional requirement that the set of agents and the set of alternatives coincide. ${ }^{1}$ That is, journals are asked to express their opinions about each other and themselves. Citations made by a journal are considered to be votes about the importance of the destination journal and a scoring method is used to aggregate the information and determine a score for each journal. Each scoring method induces a ranking rule.

In practice, the predominant scoring methods used for the measurement of intellectual influence are the impact factor (Garfield, 1955), the LP method (Liebowitz and Palmer, 1984; Laband and Piette, 1994), and the invariant method (Pinski and Narin, 1976). The last two methods generated many variations of great practical importance. The best known is the PageRank algorithm (Brin and Page, 1998), which is at the core of how search engines rank web pages. Another variation is known as the DeGroot (1974) model, which is used in models of learning in social and communication networks (Golub and Jackson, 2010), physics, and computer science (Sobel, 2000).

Despite their extensive usage, these methods have only been intuitively motivated, if at all. We are familiar with two notable exceptions which present characterizations. Given the invariant method, Palacios-Huerta and Volij (2004) find a set of cardinal properties that fully characterize it. Given the PageRank algorithm, Altman and Tennenholtz (2005) find a set of ordinal properties that fully characterize it.

This paper complements the efforts made towards a better understanding of scoring methods from a normative perspective. While we do not derive a characterization of any scoring method, we formalize a property that we

\footnotetext{
1 Note that despite the fact that the models are closely related, they lead to very different results: for example, Shoham and Leyton-Brown (2009, Proposition 9.5.1) show that Arrow's impossibility result holds exclusively in a social choice setting.
} 
call invariance to article-splitting, and with Theorem 1 we show that the impact factor, the LP method, and the invariant method do not satisfy it. ${ }^{2}$ Our result implies that there is a systematic bias common to all methods favoring journals with fewer articles (or pages, or characters). While invariance to article-splitting is a cardinal property, we show with Example 2 that if the valuations are sufficiently biased they affect the induced ordinal ranking. For the classification of academic journals, this bias against article-splitting has several implications: First, whether we control for sheer size using the number of pages or the number of articles has a profound effect on the classification results; Second, we find that quality and quantity are indistinguishable at article level; Third, it is a direct consequence of our results that the scoring methods presented are manipulable, and we suggest how in principle publishers or editors could artificially boost the scores of their journals. We also discuss how our findings can reach beyond the journal setting, to settings of great practical importance like the classification of web domains.

We then introduce modifications of all scoring methods, that are novel in the sense that we interpret a journal as an intermediary that adds value when converting inputs into outputs. These modifications also allow us to restore the desirable invariance to article splitting.

In the second part of this paper, using our modified method, we provide scores and rankings for economic journals that reflect the current trends in the influence of economic journals.

\section{Scoring Methods}

Let $J=\{1, \ldots, n\}$ denote a non-empty finite set of journals. For each $i, j \in J$, $c_{i j}$ represents the number of citations to journal $i$ by journal $j$, that is, the number of references made by journal $j$ to journal $i$. Let us consider a $n \times n$ nonnegative citation matrix $C=\left\{c_{i j}\right\}_{i, j \in J}$. Let $c_{j}=\sum_{i \in J} c_{i j}$ denote the total number of citations made by $j$ and let $D_{C}$ denote the diagonal matrix with the elements in $\left\{c_{j}\right\}_{j \in J}$ along the diagonal. Let the entries of the nonnegative vector $a$ denote the number of articles in each journal and let $A$ be the diagonal matrix with the elements in $\left\{a_{j}\right\}_{j \in J}$ along the diagonal. For each vector $z \in$ $\mathbb{R}^{n}$, we denote the 1 -norm of $z$ by $\|z\|=\sum_{i=1}^{n}\left|z_{i}\right|$.

Definition 1. A scoring problem is a triple $(J, a, C)$ consisting of a finite set of journals $J$, a vector $a \in \mathbb{N}^{n}$ containing the number of published articles and a citation matrix $C=\left\{c_{i j}\right\}_{i, j \in J}$.

Let $\mathcal{S}$ denote the set of scoring problems. The score for each journal in $J$ is given by the transposed valuations vector $v^{T}=\left(v_{1}, v_{2}, \ldots, v_{n}\right)$, where $v_{i}$ is interpreted as the value of a representative article in journal $i$.

\footnotetext{
2 Palacios-Huerta and Volij (2004) were the first to introduce invariance properties for scoring methods. However, their properties are not directly related to ours: In Step 3 of Theorem 1 we show that the invariant method, which they characterize, does not satisfy invariance to article-splitting.
} 
Definition 2. A scoring method $\phi$ maps a scoring problem $(J, a, C) \in \mathcal{S}$ to a unique valuations vector $v \in \mathbb{R}^{n}$.

A scoring method induces a weak ordering of the journals via the ranking rule $i \succcurlyeq j$ if and only if for all $i, j \in J, v_{i} \geq v_{j}$. Ties, i.e., $i \succcurlyeq j$ and $j \succcurlyeq i$, are allowed, but only occur if $v_{i}=v_{j}$.

The impact factor (Garfield, 1955) considers all citations received by an article to have the same value and measures the direct influence that a typical article in journal $i$ has on all journals.

Definition 3. The impact factor gives valuations according to $v$ that solves

$$
A^{-1} C e=v
$$

where $e$ is a vector of ones of dimension $J$ and the matrices $A$ and $C$ contain data for a two-year period.

The next two scoring methods assign different values to citations received based on the importance of the journal that made the citation. The importance of each journal is established endogenously and simultaneously for all journals in each method, using convergent iterative procedures. Roughly speaking, the LP method (Liebowitz and Palmer, 1984) gives valuations that reflect the influence that a typical article in journal $i$ has on journal $j$. The invariant method (Pinski and Narin, 1976) is a modification of the LP method such that the valuations given are also weighted by the reference intensity (i.e., the average number of citations made by a typical article in $j$ ).

For a formal presentation, we need an additional assumption and some extra notation. We require the citation matrix $C$ to be primitive ${ }^{3}$ : there should be no partition of the set of journals $J$ in two sets $J_{1}$ and $J_{2}$ such that $i$ ) there are no inter partition citations or $i i$ ) all inter partition citations are unidirectional, say from journals in $J_{2}$ to journals in $J_{1}$, and we should have at least one self-citing journal. This is a very natural and plausible assumption for classifying journals within the same field, and from a technical perspective it ensures that the following scoring methods are well defined. Under this assumption the iterative procedures defining the following two methods are known to converge. We do not follow Palacios-Huerta and Volij (2004) in requiring the citation matrix to be only non-negative and irreducible because Example 1 in Golub and Jackson (2010) shows that alone, these two assumptions do not guarantee convergence. Next, we give directly the steady-state equations.

Definition 4. The LP method gives valuations according to $v$ that solves

$$
\frac{A^{-1} C v}{\left\|A^{-1} C v\right\|}=v
$$

\footnotetext{
3 It is well known that a sufficient condition for a matrix to be primitive is to be nonnegative and irreducible with at least a positive element on the main diagonal.
} 
Definition 5. The invariant method gives valuations according to $v$ that solves

$$
A^{-1} C D_{C}^{-1} A v=v
$$

Note that all of the scoring methods that we introduced yield a measure of the intellectual influence per typical article published in a journal. However, there is a considerable heterogeneity in the length of a typical article even for journals within the same field. Some journals differ also in terms of page size. Applied studies ${ }^{4}$ correct for this by computing scores per page or per character, not per article.

\section{Article-Splitting and Manipulability}

In this section we introduce a basic desirable property of a scoring method: invariance to article-splitting. To understand this property, consider the following example in which the scoring methods yield the typical influence per page.

Example 1 (Invariance to article-splitting when scores are computed per page.)

Assume that the editorial board of a journal accepts a number of articles. Consider two scenarios: $i$ ) the articles are published as such, or $i i$ ) for some of the articles the authors are requested to shorten their length, by relegating inessential details to the "web appendix". The web appendix is available online but it is not part of the printed journal, whose length is taken as input by the scoring methods. Observe that scenario $i$ ) leads to a longer journal in terms of pages or characters than scenario $i i$ ), and that the citations made (received) by an article are invariant between scenarios, as typically there are no citations made (received) on inessential details. Invariance to article-splitting requires the score of the journal to be the same in both scenarios.

Formally, let $\lambda_{j} \in \mathbb{R}, \lambda_{j}>1$, be a splitting factor and consider two ranking problems $\left\{(J, a, C),\left(J, a^{\prime}, C\right)\right\} \subseteq \mathcal{S}$ where for some journal $j \in J, a_{j}^{\prime}=\lambda_{j} a_{j}$ and for all other journals $i \neq j, a_{i}^{\prime}=a_{i}$. Let $S=(J, a, C)$ and $S^{\prime}=\left(J, a^{\prime}, C\right)$. For the two problems $S, S^{\prime} \in \mathcal{S}$ defined as above, $S^{\prime}$ is an article-split modification of $S$.

Definition 6. A scoring method $\phi$ is invariant to article-splitting if for any two problems $S, S^{\prime} \in \mathcal{S}$ such that $S^{\prime}$ is an article-split modification of $S$, $\phi_{j}(S)=\phi_{j}\left(S^{\prime}\right)$.

Observe that the citation matrix is not affected: the number of citations does not change, they are only distributed among more papers. Thus, when the scoring methods yield the typical influence of an article, our property can be thought of as relating scoring problems in which: $i$ ) different journals have

\footnotetext{
4 See, for example, the studies of Kalaitzidakis et al (2003); Combes and Linnemer (2003); Coupé (2003).
} 
the same citation patterns but publish a different numbers of articles, or $i$ ) for the same journal, the number of articles varies. The latter interpretation simply means that if $k$ articles with no overlapping citation published in the same journal are merged into a single paper, then the resulting publication collects all citations.

Next, we define a systematic deviation from invariance to article-splitting and manipulability.

Definition 7. A scoring method $\phi$ is biased against article-splitting if for any two problems $S, S^{\prime} \in \mathcal{S}$ such that $S^{\prime}$ is an article-split modification of $S$, $\phi_{j}(S)>\phi_{j}\left(S^{\prime}\right)$.

Definition 8. A scoring method $\phi$ is manipulable if a journal can increase its valuation unilaterally.

Note that if a method is biased against article-splitting then it is manipulable.

Theorem 1. The impact factor, the LP method and the invariant method are biased against article-splitting.

Proof. Let $S, S^{\prime} \in \mathcal{S}$ be such that $S^{\prime}$ is an article-split modification of $S$. We now proceed in several (independent) steps.

Step 1: The impact factor is biased against article-splitting.

Observe that $v_{j}^{\prime}=\frac{a_{j}}{a_{j}^{\prime}} v_{j}=\frac{1}{\lambda_{j}} v_{j}$. Hence, $v_{j}^{\prime}<v_{j}$, and for all $i \neq j, v_{i}^{\prime}=v_{i}$. The result is independent of the fact that the impact factor is calculated for a period of two years.

Step 2: The LP method is biased against article-splitting.

Adapting a technique introduced by Roy et al (2008), we show that an increase in the number of articles of a journal decreases its valuation. Let $\Gamma=A^{-1} C$ and $\Gamma^{\prime}=A^{\prime-1} C$. Then, for $S$ and $S^{\prime}$, the LP method gives valuations according to vectors $v$ and $v^{\prime}$ that solve the following equations:

$$
\begin{aligned}
\Gamma v & =\|\Gamma v\| v, \\
\Gamma^{\prime} v^{\prime} & =\left\|\Gamma^{\prime} v^{\prime}\right\| v^{\prime} .
\end{aligned}
$$

Equations (4) and (5) are algebraic eigenvalue problems: $\varrho(\Gamma)=\|\Gamma v\|$ is the spectral radius of $\Gamma$ and $v$ the eigenvector associated with $\varrho(\Gamma)$, and $\varrho\left(\Gamma^{\prime}\right)=\left\|\Gamma^{\prime} v^{\prime}\right\|, \Gamma^{\prime}, v^{\prime}$ are similar. Since the matrix $\Gamma$ is primitive, $\Gamma^{\prime}$ is also primitive and (5) is well defined. Since for all $i \in J, a_{i}^{\prime} \geq a_{i}, \Gamma^{\prime}$ is weakly smaller in every entry than $\Gamma$. Therefore, there exists $\delta>0$ such that:

$$
\varrho\left(\Gamma^{\prime}\right)=\varrho(\Gamma)-\delta .
$$

We scale $v^{\prime}$ such that $v_{j}^{\prime}=v_{j}$ and rewrite $v^{\prime T}$ as $\bar{v}^{T}=v^{T}-x^{T}=\left[v_{1}-\right.$ $\left.x_{1}, \ldots, v_{j}-x_{j}, \ldots, v_{n}-x_{n}\right]$ where $x \in \mathbb{R}^{n}$ such that $x_{j}=0$. By $(5), \Gamma^{\prime} \bar{v}=\varrho\left(\Gamma^{\prime}\right) \bar{v}$. Replacing $\bar{v}, \varrho\left(\Gamma^{\prime}\right)$ and using (4), we have:

$$
\Gamma^{\prime} v-\Gamma^{\prime} x=\varrho\left(\Gamma^{\prime}\right) v-\varrho\left(\Gamma^{\prime}\right) x=\varrho(\Gamma) v-\delta v-\varrho\left(\Gamma^{\prime}\right) x=\Gamma v-\delta v-\varrho\left(\Gamma^{\prime}\right) x
$$


Let $v_{-j}, x_{-j} \in \mathbb{R}^{|J-\{j\}|}$, where $v_{i}, x_{i}>0$, be the valuation vectors except for journal $j$, and let $\Gamma_{-j}$ and $\Gamma_{-j}^{\prime}$ be the matrices $\Gamma$ and $\Gamma^{\prime}$ where we removed row and column $j$. Note that $\Gamma_{-j}=\Gamma_{-j}^{\prime}$. Dropping the $j^{\prime}$ th equation from the system of Equations 7, we obtain ${ }^{5}$ :

$$
\Gamma_{-j} x_{-j}=\delta v_{-j}+\varrho\left(\Gamma^{\prime}\right) x_{-j}
$$

Rearranging terms:

$$
\left(\varrho\left(\Gamma^{\prime}\right) I-\Gamma_{-j}\right) x_{-j}=-\delta v_{-j} .
$$

Define $N=\frac{\Gamma_{-j}}{\varrho\left(\Gamma^{\prime}\right)}$, and $M=(I-N)$. Since $\Gamma_{-j}$ and $\varrho\left(\Gamma^{\prime}\right)$ are nonnegative, $N$ is entrywise nonnegative, i.e., $N \geq 0$. Marcus and Minc (1975) show that the spectral radius of a primitive matrix is greater than the spectral radius of any of its submatrices. Hence, $\varrho\left(\Gamma^{\prime}\right)>\varrho\left(\Gamma_{-j}^{\prime}\right)=\varrho\left(\Gamma_{-j}\right)$. Thus, the moduli of the eigenvalues of $N<1$, and consequently $\lim _{t \rightarrow \infty} N^{t}=0$. But:

$$
I-N^{k+1}=M\left(I+N+N^{2}+\cdots+N^{k}\right) .
$$

Letting $k \rightarrow \infty, I=M \sum_{k=0}^{k=\infty} N^{k}$. Premultiplying by $M^{-1}$, we have $M^{-1}=\sum_{k=0}^{k=\infty} N^{k}$. Since $N \geq 0, M^{-1} \geq 0$. Observing that in (9) the vector $v_{-j}$ is positive, $x_{-j}$ has to be negative. Hence, $\bar{v}_{j}=v_{j}$ and for all $i \neq j$, $\bar{v}_{i}>v_{i}$. Rescaling $\bar{v}$ to $v^{\prime}$, we have $\frac{v_{j}^{\prime}}{v_{i}^{\prime}}<\frac{v_{j}}{v_{i}}$. Since $v_{j}^{\prime}=v_{j}$, for all $i \neq j, v_{i}^{\prime}>v_{i}$. Step 3: The invariant method is biased against article-splitting.

Observe that $v^{\prime}$, defined as $v_{j}^{\prime}=\frac{1}{\lambda_{j}} v_{j}$ and $v_{i}^{\prime}=v_{i}$ for $i \neq j$, is the solution of:

$$
A^{\prime-1} C D_{C}^{-1} A^{\prime} v^{\prime}=v^{\prime} \text {. }
$$

In order to see this, premultiply (3) by $A$, and (11) by $A^{\prime}$. Then, note that $A^{\prime} v^{\prime}=A v$. Finally observe that as $\lambda_{j}>1, v_{j}^{\prime}<v_{j}$, while the valuations of other journals have not changed.

Note that for the impact factor and for the invariant method the valuation of a journal $j$ whose articles are split into $\lambda_{j}$ articles decreases by a factor of $\frac{1}{\lambda_{j}}$. For an appropriate choice of $\lambda_{j}$, the decrease can be arbitrarily low. In particular, it can be lower than the valuation of the journal ranked next, thus changing also the ranking of the journals. Similarly, an increase in the number of articles of journal $j$ decreases its relative valuation given by the LP method, which may also affect journal $j$ 's ranking.

The following example shows that the bias against article-splitting of the scoring methods above may also induce changes in the ranking of the journals:

Example 2 (Article-splitting bias in scoring methods inducing changes in rankings).

Let $J=\left\{j_{1}, j_{2}, j_{3}\right\}, a=(2,2,3), a^{\prime}=(4,2,3)$ and define $C$ as:

\footnotetext{
${ }^{5}$ For clarity, we detail the calculations in Appendix C.
} 


$$
C=\left(\begin{array}{ccc}
12 & 8 & 4 \\
6 & 10 & 2 \\
3 & 3 & 9
\end{array}\right)
$$

Let $S=(J, a, C)$ and $S^{\prime}=\left(J, a^{\prime}, C\right)$ be two ranking problems such that $a_{1}^{\prime}=\lambda_{1} a_{1}$, with $\lambda_{1}=2$. For each problem, the following table presents the normalized vector of valuations (so that the entries add up to 1) produced by each scoring method.

\begin{tabular}{|c|cc|cc|cc|}
\hline & $\phi_{I F}(S)$ & $\phi_{I F}\left(S^{\prime}\right)$ & $\phi_{I M}(S)$ & $\phi_{I M}\left(S^{\prime}\right)$ & $\phi_{L P}(S)$ & $\phi_{L P}(S)$ \\
\hline$j_{1}$ & 0.46 & 0.30 & 0.48 & 0.31 & 0.50 & 0.29 \\
$j_{2}$ & 0.35 & 0.45 & 0.33 & 0.44 & 0.37 & 0.51 \\
$j_{3}$ & 0.19 & 0.25 & 0.19 & 0.25 & 0.13 & 0.20 \\
\hline
\end{tabular}

Note that all scoring methods induce the ranking $j_{1} \succ j_{2} \succ j_{3}$ for $S$, and $j_{2} \succ j_{1} \succ j_{3}$ for $S^{\prime}$.

Theorem 1 clearly indicates how to manipulate scoring methods. Should the methods take as input the number of articles, then editors might opt to implement a policy of publishing a small number of articles. If the number of pages (or characters) is taken as input, then preference can be given to publishing briefer communications. Recall Example 1. In principle, editors' requests of discarding inessential details by relegating them to the web appendix are desirable, as we don't want to waste valuable resources such as journal pages and reader's time for irrelevant details. However, the same requests might easily be abused to game the scoring methods. Interestingly, essentially the same methods are used by search engines for obtaining the ranking of web pages. The following example aims to clarify this analogy.

\section{Example 3 (The ranking of web domains.)}

A professor makes the following types of information available online: research, teaching, and contact details. There are two natural options: $i$ ) to put all available information on one page, each type in a separate section, or $i i$ ) to create one distinct web page for each type. ${ }^{6}$ Search engines, like Google or Bing, use essentially the same methods as the one used for the ranking of academic journals: their algorithm relies on the LP-method where the left eigenvector is computed, i.e., the weight for each page is given by the components of vector $v$ that solves $\frac{v A^{-1} C^{T}}{\left\|v A^{-1} C^{T}\right\|}=v$, where each entry $c_{i j}$ in the transposed matrix $C^{T}$ can be thought of as the number of links made by domain $i$ to domain $j$ out of the total links made by $i$, and $a_{i}$ as the number of web pages per domain. ${ }^{7}$ By Theorem 1, it is a dominant strategy for the professor to aggregate all information on a single page. The same technique used in Step 2 of Theorem 1

\footnotetext{
6 Note that this professor is only interested in the ranking of his domain and that the links that his domain typically makes/receives are invariant in both cases.

7 The exact algorithms used by search engines are both a moving target and a black box, but the characteristics to which we make the analogy to here are known to be relatively stable (see for example Langville and Meyer (2006)).
} 
can be easily adapted for the left eigenvector and leads to the same qualitative conclusions.

More generally, owners of web domains have incentives to manipulate for economic profit: a higher placement in Google results drives more internet traffic which in turn yields higher sales or advertisement revenues. Reinterpreting Theorem 1 in this context reveals that a domain owner can improve the score for his domain by jamming all his data on a single omniscient sheet.

\section{Modified Scoring Methods}

All the methods introduced in the previous section measure the typical influence of an article in $i$ over journal $j$. In each method, every journal $i$ is viewed as an initial creator of knowledge, where the unit of knowledge created is a typical article in $i$. There are two important flaws with this interpretation. First, it assumes that journals use no inputs: this approach would be suitable in a world where each article would be $100 \%$ original and would not draw on any pre-existing insights; even if such a world would exist, then we would have an inconsistency because if all articles are entirely original there are no citations made. Second, if articles can be split or merged, an article is surely not the the most elementary building block of a journal. This problem has been previously addressed by counting journal pages, or - given that pages can be very different in size - even characters. Mirrlees et al (2003) is an excellent survey of empiric works that use such approaches. However, the character length is natural to measure the length of an essay, but not papers, especially in a field so diverse as economics.

Theorem 1 together with the discussion above are not just criticizing the most used ranking methods, but they are also instructive about where to improve. In the following, we will define modified methods that are invariant to article-splitting. First, we view a journal as an intermediary that adds value when converting inputs (citations made) into outputs (citations received). Interpreting a journal as an intermediary is new. In spirit, this idea is related to the stream of research in the management literature that focuses on measuring the value of intangible assets (for instance, human capital in a consultancy company): since a direct measurement is impossible, the ability of these intangible assets to convert inputs into outputs is often taken as proxy for their value. Similarly, we proxy the creation of new knowledge by a journal's ability to convert inputs into outputs. Second, we consider the smallest indivisible unit of knowledge to be a citation. Thus, we take the number of citations made as the footprint of an article and of a journal, and we value those articles more that can make the most of the same borrowed knowledge. Formally, we define:

Definition 9. The modified impact factor gives valuations according to $v$ that solves

$$
D_{C}^{-1} C e=v
$$


where $e$ is a vector of ones of dimension $J$ and the matrices $D_{C}$ and $C$ contain data for a two-year period.

Definition 10. The modified LP method gives valuations according to $v$ that solves

$$
\frac{D_{C}^{-1} C v}{\left\|D_{C}^{-1} C v\right\|}=v .
$$

Definition 11. The modified invariant method gives valuations according to $v$ that solves

$$
D_{C}^{-1} C D_{C}^{-1} D_{C} v=v .
$$

The invariant method simplifies to $D_{C}^{-1} C v=v$. Since the matrix $D_{C}^{-1} C$ is normalized we have the following remark.

Remark 1 The modified invariant and modified LP methods coincide.

\section{Rankings of Economic Journals}

In this section we provide scores and rankings for economic journals.

\subsection{Data}

Our data is based on the category "Economics" in the Journal Citation Reports $(J C R)$ of Thompson-Reuters. We have ignored citations to and from journals outside this category. The data is published annually with a one year lag: edition $t$ appears in year $t+1$ and contains data about publications that appeared in $t$. Our data is for the editions from 2002 to 2010.

From this data, we excluded (1) "ghost" journals, i.e., journals for which the sum of citations made and received is at most 2, (2) "dead" journals that do not make citations in a given year and (3) new journals, i.e., journals that only appear in latest edition of the data. Following this approach, we obtained a set of 224 journals that make or receive citations and that appeared in at least two years of our data.

Notice that an article published in a journal in year $t$ may make citations to articles published in any year $t^{\prime}, t^{\prime} \leq t$. In particular, some relatively old articles had a persistent impact, and receive an important number of citations even many years after their publication. However, we are interested in the current quality of economic journals. Thus, we ignore citations to old articles as follows: for each year $t \in\{2006, \ldots 2010\}$, we generate matrices of citations $C^{t}$, where an entry $c_{i j}^{t}$ is the total number of citations made by $j$ in year $t$ to articles published in $i$ in all years $t^{\prime}$, such that $t-t^{\prime} \leq 4$. That is, to compute the scores for 2010, we used only citations made by articles published in 2010 to articles that appeared between 2006 and 2010 inclusive.

For completeness, in Appendix B we include a description of how we formatted the data for input, and we provide the source code that we used for our computations. 
5.2 The Influence of Economic Journals

In Table 1, for the top 30 journals, we present the development of the modified invariant scores over the last 5 years. To ease the comparison, we use normalized vectors: scores are given in percents. The complete table with the full set of 224 journals is presented in Appendix A.

Table 1: Modified invariant scores (sc) and ranks (r) of economic journals, 2006-2010.

\begin{tabular}{|c|c|c|c|c|c|c|c|c|c|c|}
\hline \multirow[b]{2}{*}{ Journal } & \multicolumn{2}{|c|}{2006} & \multicolumn{2}{|c|}{2007} & \multicolumn{2}{|c|}{2008} & \multicolumn{2}{|c|}{2009} & \multicolumn{2}{|c|}{2010} \\
\hline & $\mathrm{sc}$ & $\mathrm{r}$ & $\mathrm{sc}$ & $\mathrm{r}$ & $\mathrm{sc}$ & $\mathrm{r}$ & $\mathrm{sc}$ & $\mathrm{r}$ & $\mathrm{sc}$ & $\mathrm{r}$ \\
\hline Econometrica & 6.62 & 1 & 4.94 & 2 & 5.56 & 2 & 4.13 & 2 & 4.51 & 1 \\
\hline J Polit Econ & 6.31 & 2 & 12.41 & 1 & 5.59 & 1 & 4.77 & 1 & 4.17 & 2 \\
\hline Q J Econ & 5.09 & 3 & 3.99 & 3 & 4.27 & 3 & 3.83 & 3 & 4.10 & 3 \\
\hline Rev Econ Stud & 3.12 & 5 & 3.47 & 5 & 3.16 & 4 & 3.17 & 5 & 2.83 & 4 \\
\hline Am Econ Rev & 2.62 & 6 & 3.37 & 6 & 2.83 & 5 & 3.00 & 7 & 2.81 & 5 \\
\hline J Labor Econ & 2.07 & 10 & 1.77 & 12 & 2.77 & 6 & 1.79 & 14 & 2.56 & 6 \\
\hline $\mathrm{J}$ Financ & - & 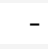 & - & 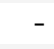 & - & - & 3.21 & 4 & 2.55 & 7 \\
\hline J Law Econ Organ & 1.28 & 22 & 3.07 & 7 & 0.77 & 37 & 0.76 & 40 & 2.34 & 8 \\
\hline Rand J Econ & 1.97 & 11 & 0.95 & 28 & 1.41 & 17 & 3.11 & 6 & 2.32 & 9 \\
\hline J Law Econ & 1.28 & 21 & 3.86 & 4 & 0.50 & 53 & 0.80 & 38 & 2.24 & 10 \\
\hline Rev Econ Stat & 2.35 & 7 & 2.07 & 9 & 2.51 & 7 & 1.94 & 13 & 1.95 & 11 \\
\hline Math Financ & 1.12 & 25 & 0.66 & 41 & 1.37 & 20 & 0.92 & 30 & 1.89 & 12 \\
\hline J Econ Perspect & 1.64 & 15 & 1.42 & 14 & 2.23 & 10 & 2.63 & 8 & 1.85 & 13 \\
\hline J Econ Theory & 4.27 & 4 & 1.32 & 15 & 2.34 & 8 & 1.54 & 16 & 1.71 & 14 \\
\hline $\mathrm{J}$ Econometrics & 1.04 & 27 & 1.01 & 25 & 0.77 & 36 & 2.01 & 11 & 1.68 & 15 \\
\hline Int J Game Theory & 0.38 & 69 & 0.38 & 60 & 0.22 & 94 & 1.65 & 15 & 1.66 & 16 \\
\hline Econ Theor & 1.04 & 28 & 0.94 & 29 & 1.23 & 23 & 1.50 & 17 & 1.63 & 17 \\
\hline J Financ Econ & 2.30 & 9 & 1.16 & 20 & 2.34 & 9 & 2.36 & 9 & 1.59 & 18 \\
\hline Int Econ Rev & 2.32 & 8 & 1.60 & 13 & 2.03 & 12 & 1.04 & 27 & 1.58 & 19 \\
\hline J Eur Econ Assoc & - & - & 1.88 & 11 & 1.67 & 15 & 1.18 & 22 & 1.55 & 20 \\
\hline J Monetary Econ & 1.68 & 14 & 0.88 & 32 & 1.12 & 26 & 1.31 & 21 & 1.54 & 21 \\
\hline Soc Choice Welfare & 0.53 & 52 & 0.71 & 38 & 0.43 & 56 & 0.75 & 41 & 1.46 & 22 \\
\hline Exp Econ & 0.50 & 53 & 1.11 & 23 & 0.68 & 41 & 1.09 & 24 & 1.40 & 23 \\
\hline J Bus Econ Stat & 1.37 & 19 & 0.80 & 35 & 1.85 & 14 & 0.65 & 45 & 1.35 & 24 \\
\hline J Hum Resour & 0.80 & 38 & 1.14 & 21 & 1.05 & 27 & 1.41 & 20 & 1.33 & 25 \\
\hline $\mathrm{J}$ Int Econ & 1.02 & 30 & 1.10 & 24 & 0.94 & 31 & 0.90 & 32 & 1.21 & 26 \\
\hline Brookings P Eco Ac & 1.11 & 26 & 0.99 & 26 & 1.88 & 13 & 1.43 & 19 & 1.19 & 27 \\
\hline $\mathrm{J}$ Ind Econ & 1.37 & 18 & 0.91 & 30 & 0.74 & 39 & 0.90 & 32 & 1.18 & 28 \\
\hline Game Econ Behav & 1.92 & 13 & 2.34 & 8 & 1.41 & 18 & 1.13 & 23 & 1.18 & 29 \\
\hline J Econ Growth & 0.54 & 49 & 1.93 & 10 & 2.21 & 11 & 1.04 & 26 & 1.11 & 30 \\
\hline
\end{tabular}

For the most recent results of 2010, the modified invariant method ranks high journals such as IJGT or Social Choice and Welfare. These are rather 
formal journals that require relatively little input and are very efficient in converting inputs into outputs. In contrast, the modified invariant method ranks less high journals such as Brookings Papers on Economic Activity or the Journal of Economic Literature. These journals naturally require extensive reviews of the literature. Given the sheer number of inputs needed, these journals are less efficient in converting inputs into outputs.

We also note the excellent results obtained in 2010 by the Journal of Law, Economics and Organization (JLEO). This was particularly surprising since this journal rather falls in the category of journals that require extensive reviews of the literature. A close inspection reveals that despite making a relatively high number of citations, only a fraction of these citations are towards other journals that are included in our dataset, i.e., an important number of cites are to law and management journals. Thus, for our method, this journal appears to consume less information than it actually does. A similar observation applies for the Mathematical Finance (MF), a journal that has an important fraction of citations to journals in mathematics and statistics. On the other hand, JLEO and MF receive a lot of attention from other journals in economics. It seems that both these journals are very efficient in converting input from other disciplines to economics.

When we look at the trends in the intellectual influence of economic journals, while we see a slight permutation in the rankings, the top five remained relatively stable between 2006 and 2010. The same cannot be said about all other journals. Over the years studied, the International Journal of Game Theory (IJGT) has made a remarkable progress, overtaking even Games and Economic Behavior (GEB), widely considered a top journal. While one can only speculate about the reasons of these changes, favorable editorial policies expanding the journal's scope into niche segments on the one side, and an increasing competition from among others the newly launched American Economic Journal: Microeconomics on the other, may have contributed to these developments.

The Journal of Finance was continuously published since 1946. However, our dataset only contains enough information to provide results for this journal for two years. As we are unsure about why the dataset is incomplete, we are cautious in interpreting the scores for this journal.

We also note that all scores and rankings based on eigenvector methods, irrespective of whether these methods are modified or unmodified, are inherently volatile. We could reduce the volatility by increasing the difference $t-t^{\prime}$, but this would be against our scope of providing current, as opposed to historical, scores. Another way to reduce the volatility would be to introduce correction factors. If the citation matrix would have dangling nodes, i.e., journals that only receive but do not make citations, one could introduce a correction factor that allows with some probability to "escape" from the dangling node. In principle this technique can be extended even for matrices such as ours where all journals make citations to smoothen out the scores. However, since there is a trade off between introducing noise and smoothening scores, calibrating the correction factor would be of paramount importance. 


\subsection{Other Scores and Rankings}

In this subsection, we discuss some other scores and rankings that are sometimes used.

Thomson Reuters publishes an impact factor score (see Definition 3) for journals. This is the score displayed on the webpages of journals at major publishers. Research Papers in Economics (RePEc) is the largest bibliographical database in Economics, covering most journals and working papers. RePEc provides a number of alternative scores based on a time unrestricted impact factor (Zimmermann, 2007).

Recall that for the impact factor, there is no distinction if a citation is received from a prestigious journal or from a mediocre one, i.e., all citations have equal weight. Furthermore, the impact factor is just an average. It is known to vary greatly across and even within fields due to, for instance, differences in citation habits and field size (Jemec, 2001). Moreover, it is so easily manipulable that in 2007, as a form of protest against it's usage, the editorial board of a medical journal agreed to publish one article that alone boosted it's impact factor from 0.66 to 1.44 (Opátrný, 2008). Despite this protest, in 2008, the journal Acta Crystallographica Section A ranked second in Thomson Reuter's science category, ahead of journals such as Nature or Science, after publishing one article in which the authors suggested that their work can be used as a general reference for an emerging field. Overall, the limitations by definition and the forms of potential and real manipulation (Smith, 1997) make the impact factor a very unreliable indicator of quality.

Palacios-Huerta and Volij (2004) characterized the invariant method and provided rankings of economic journals using different methods. In their rankings, Palacios-Huerta and Volij (2004) used a subset of 37 journals and in their $C^{t}$ matrix they allowed for any $t^{\prime}$ such that $t-t^{\prime} \leq 6$. However, note that Palacios-Huerta and Volij (2004) are only interested in illustrating the differences between the methods they consider. Thus, for simplicity and to ease the computations, it was natural for them to restrict their attention to a small arbitrary subset of journals. Their results are not meant to reflect the intellectual influence of economic journals.

The EigenFactor (Bergstrom, 2007; Bergstrom et al, 2008) and the SCImago (González-Pereira et al, 2009) are two independent projects that are worth mentioning as real contributions towards the understanding of the influence of journals. Based on data from Thomson Reuters and Elsevier's Scopus respectively ${ }^{8}$, both projects essentially use fine-tuned invariant methods to obtain scores and rankings for journals. Despite the fact that the methodology in both projects is subject to the same critiques as the invariant method, these projects represent a major improvement over the impact factor.

\footnotetext{
8 Unfortunately, for the time being, metrics based on automatically identified citations using Google Scholar or RePEc just add one more layer of uncertainty, namely collecting genuine citations.
} 
Finally, we note that the tournament method (Kóczy and Strobel, 2010) is invariant to article-splitting by definition, and that for the $h$ index (Hirsch, 2004; Braun et al, 2006) article splitting has an ambiguous effect.

\section{Conclusion}

This paper is part of a broader program that aims at the better understanding of scoring methods. Kóczy and Strobel (2008) have shown that adding unnecessary citations may be a means of manipulation, here we look at an issue of journal design: the length of the articles.

First, we introduced and formalized a desirable property and we derived analytically that the popular methods for ranking academic journals are inherently biased. For journals with similar citation patterns, the journals publishing fewer articles are privileged to the ones publishing more articles. If we account for the length of a journal based on the number of pages or characters, then the current scoring methods give extra credit to shorter more formal journals and punish those that make an effort of keeping good English in their articles. Thus, the currently most used scoring methods share a common drawback: they cannot distinguish quality from quantity at article level. Furthermore, observe that for a journal with relatively numerous articles but few pages, measuring its influence by taking the number of pages or articles as input will make a crucial difference. One must therefore use and interpret the valuations and the induced rankings with care when estimating the quality of journals and articles.

A direct consequence of our theoretical results is that the current methods for measuring influence are manipulable, and that strategies that increase the payoffs are relatively easy to infer and implement. This is a concern for the evaluation of research and in closely related settings like raking web domains. An interesting open question is to quantify the incentive to manipulate by considering the maximum number of ranks someone can gain in their preference ordering by manipulation or the number of ranks someone else can lose due to manipulation, as it has recently been done by (Campbell and Kelly, 2009, 2010) for social choice settings.

Second, we introduced a modification of the current scoring methods which renders them immune to the bias and which, as opposed to other modifications suggested in the earlier literature, still preserves the notion of value at article level. This modification has also a novel interpretation, and it is more appropriate for measuring the creation of knowledge.

Third, using our modified invariant method, we have conducted a worldwide ranking of journals in economics, over the period 2006-2010.

\section{Appendix}

A The complete ranking of economics journals 
Table 2: Modified invariant scores (sc) and ranks (r) of economic journals, 2006-2010.

\begin{tabular}{|c|c|c|c|c|c|c|c|c|c|c|}
\hline \multirow[b]{2}{*}{ Journal } & \multicolumn{2}{|c|}{2006} & \multicolumn{2}{|c|}{2007} & \multicolumn{2}{|c|}{2008} & \multicolumn{2}{|c|}{2009} & \multicolumn{2}{|c|}{2010} \\
\hline & $\mathrm{sc}$ & $\mathrm{r}$ & $\mathrm{sc}$ & $\mathrm{r}$ & $\mathrm{sc}$ & $\mathrm{r}$ & $\mathrm{sc}$ & $\mathrm{r}$ & $\mathrm{sc}$ & $\mathrm{r}$ \\
\hline Econometrica & 6.62 & 1 & 4.94 & 2 & 5.56 & 2 & 4.13 & 2 & 4.51 & 1 \\
\hline J Polit Econ & 6.31 & 2 & 12.41 & 1 & 5.59 & 1 & 4.77 & 1 & 4.17 & 2 \\
\hline Q J Econ & 5.09 & 3 & 3.99 & 3 & 4.27 & 3 & 3.83 & 3 & 4.10 & 3 \\
\hline Rev Econ Stud & 3.12 & 5 & 3.47 & 5 & 3.16 & 4 & 3.17 & 5 & 2.83 & 4 \\
\hline Am Econ Rev & 2.62 & 6 & 3.37 & 6 & 2.83 & 5 & 3.00 & 7 & 2.81 & 5 \\
\hline J Labor Econ & 2.07 & 10 & 1.77 & 12 & 2.77 & 6 & 1.79 & 14 & 2.56 & 6 \\
\hline J Financ & - & - & - & - & - & - & 3.21 & 4 & 2.55 & 7 \\
\hline J Law Econ Organ & 1.28 & 22 & 3.07 & 7 & 0.77 & 37 & 0.76 & 40 & 2.34 & 8 \\
\hline Rand J Econ & 1.97 & 11 & 0.95 & 28 & 1.41 & 17 & 3.11 & 6 & 2.32 & 9 \\
\hline J Law Econ & 1.28 & 21 & 3.86 & 4 & 0.50 & 53 & 0.80 & 38 & 2.24 & 10 \\
\hline Rev Econ Stat & 2.35 & 7 & 2.07 & 9 & 2.51 & 7 & 1.94 & 13 & 1.95 & 11 \\
\hline Math Financ & 1.12 & 25 & 0.66 & 41 & 1.37 & 20 & 0.92 & 30 & 1.89 & 12 \\
\hline $\mathrm{J}$ Econ Perspect & 1.64 & 15 & 1.42 & 14 & 2.23 & 10 & 2.63 & 8 & 1.85 & 13 \\
\hline J Econ Theory & 4.27 & 4 & 1.32 & 15 & 2.34 & 8 & 1.54 & 16 & 1.71 & 14 \\
\hline $\mathrm{J}$ Econometrics & 1.04 & 27 & 1.01 & 25 & 0.77 & 36 & 2.01 & 11 & 1.68 & 15 \\
\hline Int J Game Theory & 0.38 & 69 & 0.38 & 60 & 0.22 & 94 & 1.65 & 15 & 1.66 & 16 \\
\hline Econ Theor & 1.04 & 28 & 0.94 & 29 & 1.23 & 23 & 1.50 & 17 & 1.63 & 17 \\
\hline J Financ Econ & 2.30 & 9 & 1.16 & 20 & 2.34 & 9 & 2.36 & 9 & 1.59 & 18 \\
\hline Int Econ Rev & 2.32 & 8 & 1.60 & 13 & 2.03 & 12 & 1.04 & 27 & 1.58 & 19 \\
\hline J Eur Econ Assoc & - & - & 1.88 & 11 & 1.67 & 15 & 1.18 & 22 & 1.55 & 20 \\
\hline J Monetary Econ & 1.68 & 14 & 0.88 & 32 & 1.12 & 26 & 1.31 & 21 & 1.54 & 21 \\
\hline Soc Choice Welfare & 0.53 & 52 & 0.71 & 38 & 0.43 & 56 & 0.75 & 41 & 1.46 & 22 \\
\hline Exp Econ & 0.50 & 53 & 1.11 & 23 & 0.68 & 41 & 1.09 & 24 & 1.40 & 23 \\
\hline J Bus Econ Stat & 1.37 & 19 & 0.80 & 35 & 1.85 & 14 & 0.65 & 45 & 1.35 & 24 \\
\hline J Hum Resour & 0.80 & 38 & 1.14 & 21 & 1.05 & 27 & 1.41 & 20 & 1.33 & 25 \\
\hline $\mathrm{J}$ Int Econ & 1.02 & 30 & 1.10 & 24 & 0.94 & 31 & 0.90 & 32 & 1.21 & 26 \\
\hline Brookings $\mathrm{P}$ Econ Ac & 1.11 & 26 & 0.99 & 26 & 1.88 & 13 & 1.43 & 1 & 1.19 & 27 \\
\hline $\mathrm{J}$ Ind Econ & 1.37 & 18 & 0.91 & 30 & 0.74 & 39 & 0.90 & 32 & 1.18 & 28 \\
\hline Game Econ Behav & 1.92 & 13 & 2.34 & 8 & 1.41 & 18 & 1.13 & 23 & 1.18 & 29 \\
\hline J Econ Growth & 0.54 & 49 & 1.93 & 10 & 2.21 & 11 & 1.04 & 26 & 1.11 & 30 \\
\hline Economet Theor & 1.01 & 32 & 1.13 & 22 & 1.02 & 28 & 0.93 & 29 & 1.09 & 31 \\
\hline Economica & 0.67 & 43 & 0.35 & 64 & 0.30 & 75 & 0.53 & 55 & 0.97 & 32 \\
\hline Econ Philos & 1.03 & 29 & 0.15 & 102 & 0.05 & 167 & 0.08 & 156 & 0.93 & 33 \\
\hline J Public Econ & 1.19 & 23 & 1.18 & 19 & 0.88 & 32 & 0.80 & 37 & 0.90 & 34 \\
\hline IMF Staff Papers & 0.23 & 84 & 0.34 & 67 & 0.60 & 48 & 0.12 & 128 & 0.88 & 35 \\
\hline Econ J & 1.30 & 20 & 0.82 & 34 & 0.95 & 30 & 0.88 & 33 & 0.87 & 36 \\
\hline $\mathrm{J}$ Financ Economet & - & - & - & - & - & - & 1.03 & 28 & 0.83 & 37 \\
\hline Rev Econ Dynam & 1.38 & 17 & 1.31 & 16 & 1.38 & 19 & 1.97 & 12 & 0.82 & 38 \\
\hline Economet Rev & - & - & 0.33 & 68 & 0.74 & 39 & 2.29 & 10 & 0.79 & 39 \\
\hline J Dev Econ & 0.67 & 44 & 0.79 & 36 & 1.18 & 25 & 0.72 & 43 & 0.73 & 40 \\
\hline Economet J & - & - & 0.62 & 43 & 0.34 & 71 & 0.26 & 79 & 0.71 & 41 \\
\hline $\mathrm{J}$ Econ Lit & 1.39 & 16 & 1.18 & 19 & 1.35 & 21 & 0.56 & 53 & 0.71 & 42 \\
\hline J Money Credit Bank & 0.37 & 71 & 0.38 & 58 & 1.23 & 22 & 0.70 & 44 & 0.70 & 43 \\
\hline Quant Mark Econ & - & - & - & - & 0.43 & 55 & 0.08 & 154 & 0.66 & 44 \\
\hline J Appl Economet & - & - & - & - & - & - & 0.85 & 36 & 0.65 & 45 \\
\hline J Account Econ & 1.93 & 12 & 0.97 & 27 & 0.77 & 35 & 1.43 & 19 & 0.65 & 46 \\
\hline $\mathrm{J}$ Econ Hist & 0.63 & 46 & 1.25 & 17 & 1.62 & 16 & 0.74 & 42 & 0.64 & 47 \\
\hline J Econ Manage Strat & 0.87 & 35 & 0.51 & 49 & 0.66 & 44 & 0.34 & 67 & 0.64 & 48 \\
\hline Int $\mathrm{J}$ Ind Organ & 0.59 & 48 & 0.37 & 61 & 0.45 & 54 & 0.87 & 34 & 0.62 & 49 \\
\hline Eur Econ Rev & 0.85 & 37 & 0.54 & 47 & 0.82 & 34 & 0.64 & 47 & 0.62 & 50 \\
\hline J Urban Econ & 0.71 & 42 & 0.74 & 37 & 0.32 & 74 & 0.77 & 39 & 0.57 & 51 \\
\hline Econ Policy & 0.44 & 62 & 0.31 & 71 & 0.58 & 51 & 0.35 & 65 & 0.56 & 52 \\
\hline
\end{tabular}


Table 2 - continued from previous page

\begin{tabular}{|c|c|c|c|c|c|c|c|c|c|c|}
\hline \multirow[b]{2}{*}{ Journal } & \multicolumn{2}{|c|}{2006} & \multicolumn{2}{|c|}{2007} & \multicolumn{2}{|c|}{2008} & \multicolumn{2}{|c|}{2009} & \multicolumn{2}{|c|}{2010} \\
\hline & $\mathrm{sc}$ & $\mathrm{r}$ & $\mathrm{sc}$ & $\mathrm{r}$ & $\mathrm{sc}$ & $\mathrm{r}$ & $\mathrm{sc}$ & $\mathrm{r}$ & $\mathrm{sc}$ & $\mathrm{r}$ \\
\hline J Financ Quant Anal & 1.02 & 31 & 0.85 & 33 & 0.98 & 29 & 0.87 & 35 & 0.50 & 54 \\
\hline Econ Hist Rev & 0.32 & 75 & 0.17 & 95 & 0.59 & 49 & 0.34 & 69 & 0.50 & 54 \\
\hline Theor Decis & 0.21 & 85 & 0.24 & 77 & 0.32 & 73 & 1.05 & 25 & 0.50 & 55 \\
\hline Econ Inq & 0.45 & 61 & 0.62 & 43 & 0.70 & 40 & 0.57 & 51 & 0.49 & 56 \\
\hline Econ Dev Cult Change & 0.13 & 108 & 0.43 & 54 & 0.40 & 62 & 0.43 & 61 & 0.47 & 57 \\
\hline Econ Lett & 0.61 & 47 & 0.67 & 39 & 0.34 & 69 & 0.60 & 48 & 0.46 & 58 \\
\hline J Risk Uncertainty & 0.87 & 34 & 0.53 & 48 & 0.66 & 43 & 0.39 & 62 & 0.46 & 59 \\
\hline J Health Econ & 0.54 & 51 & 0.35 & 65 & 0.42 & 59 & 0.34 & 66 & 0.45 & 60 \\
\hline Scand J Econ & 0.77 & 40 & 0.43 & 53 & 0.65 & 45 & 0.25 & 82 & 0.42 & 61 \\
\hline J Env Econ Manag & 0.48 & 56 & 0.48 & 51 & 0.36 & 66 & 0.34 & 69 & 0.41 & 62 \\
\hline J Econ Educ & 0.18 & 93 & 0.06 & 147 & 0.38 & 64 & 0.07 & 163 & 0.39 & 63 \\
\hline Public Choice & 0.25 & 81 & 0.22 & 81 & 0.28 & 80 & 0.19 & 99 & 0.39 & 64 \\
\hline Can J Econ & 0.33 & 73 & 0.23 & 78 & 0.29 & 77 & 0.27 & 75 & 0.37 & 65 \\
\hline J Math Econ & 0.77 & 39 & 0.60 & 45 & 0.63 & 47 & 0.58 & 50 & 0.34 & 66 \\
\hline World Bank Econ Rev & 0.26 & 77 & 0.60 & 44 & 0.55 & 52 & 0.56 & 54 & 0.34 & 67 \\
\hline J Econ Behav Organ & 0.50 & 54 & 0.89 & 31 & 0.40 & 63 & 0.38 & 63 & 0.33 & 68 \\
\hline Econ Educ Rev & 0.49 & 55 & 0.32 & 70 & 0.59 & 50 & 0.24 & 84 & 0.33 & 69 \\
\hline J Risk Insur & 0.26 & 79 & 0.23 & 79 & 0.17 & 100 & 0.17 & 103 & 0.32 & 70 \\
\hline Explor Econ Hist & 0.40 & 64 & 0.40 & 57 & 1.21 & 24 & 0.13 & 121 & 0.31 & 71 \\
\hline J Jpn Int Econ & 0.08 & 123 & 0.21 & 85 & 0.16 & 105 & 0.11 & 133 & 0.30 & 72 \\
\hline J Public Econ Theory & - & - & - & - & - & - & 0.25 & 81 & 0.30 & 73 \\
\hline Oxford B Econ Stat & 0.19 & 89 & 0.36 & 63 & 0.32 & 72 & 0.49 & 58 & 0.29 & 74 \\
\hline Econ Soc & 0.18 & 91 & 0.10 & 123 & 0.06 & 146 & 0.10 & 137 & 0.29 & 75 \\
\hline J Policy Anal Manag & - & - & 0.08 & 131 & 0.28 & 79 & 0.29 & 73 & 0.28 & 77 \\
\hline Indep Rev & - & - & 0.10 & 121 & 0.09 & 135 & 0.01 & 209 & 0.28 & 77 \\
\hline J Econ Dyn Control & 0.48 & 58 & 0.41 & 56 & 0.34 & 70 & 0.45 & 59 & 0.28 & 78 \\
\hline Eur Rev Econ Hist & - & - & - & - & - & - & 0.26 & 78 & 0.27 & 79 \\
\hline Rev Env Econ Policy & - & - & _ & - & - & - & 0.04 & 185 & .27 & 80 \\
\hline Macroecon Dyn & 0.36 & 72 & 0.32 & 69 & 0.28 & 81 & 0.13 & 125 & 0.25 & 81 \\
\hline Econ J Watch & - & - & - & - & - & - & 0.04 & 182 & 0.24 & 82 \\
\hline Fisc Stud & 0.14 & 102 & 0.04 & 160 & 0.10 & 131 & 0.23 & 91 & 0.24 & 83 \\
\hline Natl Tax J & 0.86 & 36 & 0.18 & 89 & 0.64 & 46 & 0.29 & 74 & 0.24 & 84 \\
\hline Quant Financ & 0.64 & 45 & 0.31 & 72 & 0.17 & 101 & 0.18 & 101 & 0.23 & 85 \\
\hline J Popul Econ & 0.26 & 78 & 0.38 & 59 & 0.41 & 61 & 0.65 & 46 & 0.23 & 86 \\
\hline J Transp Econ Policy & 0.11 & 116 & 0.27 & 74 & 0.16 & 104 & 0.60 & 49 & 0.22 & 87 \\
\hline Fem Econ & 0.06 & 131 & 0.05 & 150 & 0.01 & 183 & 0.09 & 149 & 0.22 & 89 \\
\hline Oxford Econ Pap & 0.47 & 60 & 0.49 & 50 & 0.87 & 33 & 0.24 & 89 & 0.22 & 89 \\
\hline Int Tax Public Finan & 0.48 & 57 & 0.29 & 73 & 0.27 & 82 & 0.24 & 86 & 0.22 & 90 \\
\hline Reg Sci Urban Econ & 0.15 & 99 & 0.46 & 52 & 0.37 & 65 & 0.16 & 107 & 0.21 & 91 \\
\hline J Econ Geogr & 0.40 & 67 & 0.09 & 128 & 0.24 & 89 & 0.16 & 108 & 0.21 & 92 \\
\hline Labour Econ & 0.43 & 63 & 0.34 & 66 & 0.21 & 95 & 0.31 & 72 & 0.21 & 93 \\
\hline Real Estate Econ & 1.15 & 24 & 0.04 & 157 & 0.17 & 103 & 0.36 & 64 & 0.20 & 95 \\
\hline South Econ J & 0.16 & 96 & 0.18 & 90 & 0.25 & 87 & 0.16 & 107 & 0.20 & 95 \\
\hline Small Bus Econ & 0.06 & 134 & 0.21 & 84 & 0.08 & 139 & 0.10 & 141 & 0.19 & 96 \\
\hline Am J Agr Econ & 0.13 & 103 & 0.22 & 83 & 0.24 & 92 & 0.15 & 113 & 0.19 & 97 \\
\hline J Macroecon & 0.12 & 115 & 0.08 & 133 & 0.09 & 137 & 0.11 & 131 & 0.19 & 98 \\
\hline Econ Dev Q & 0.03 & 148 & 0.67 & 40 & 0.00 & 194 & 0.04 & 184 & 0.19 & 99 \\
\hline Rev Dev Econ & - & - & 0.11 & 120 & 0.13 & 114 & 0.21 & 94 & 0.17 & 100 \\
\hline J Real Estate Financ & 0.48 & 59 & 0.07 & 138 & 0.21 & 96 & 0.15 & 111 & 0.17 & 102 \\
\hline Health Econ & 0.19 & 90 & 0.13 & 111 & 0.41 & 60 & 0.27 & 76 & 0.17 & 102 \\
\hline Am J Econ Sociol & 0.01 & 153 & 0.15 & 103 & 0.08 & 142 & 0.19 & 98 & 0.17 & 103 \\
\hline Int J Forecasting & 0.40 & 66 & 0.12 & 114 & 0.11 & 123 & 0.09 & 145 & 0.16 & 104 \\
\hline Oxford Rev Econ Pol & 0.15 & 99 & 0.22 & 80 & 0.23 & 93 & 0.15 & 109 & 0.16 & 105 \\
\hline Jpn Econ Rev & 0.08 & 124 & 0.20 & 87 & 0.35 & 68 & 0.02 & 194 & 0.16 & 106 \\
\hline
\end{tabular}


Table 2 - continued from previous page

\begin{tabular}{|c|c|c|c|c|c|c|c|c|c|c|}
\hline \multirow[b]{2}{*}{ Journal } & \multicolumn{2}{|c|}{2006} & \multicolumn{2}{|c|}{2007} & \multicolumn{2}{|c|}{2008} & \multicolumn{2}{|c|}{2009} & \multicolumn{2}{|c|}{2010} \\
\hline & $\mathrm{sc}$ & $\mathrm{r}$ & $\mathrm{sc}$ & $\mathrm{r}$ & $\mathrm{sc}$ & $\mathrm{r}$ & $\mathrm{sc}$ & $\mathrm{r}$ & $\mathrm{sc}$ & $\mathrm{r}$ \\
\hline Fed Reserve Bank St & - & - & - & - & 0.43 & 57 & 0.22 & 93 & 0.15 & 107 \\
\hline Appl Econ & 0.05 & 135 & 0.10 & 124 & 0.13 & 117 & 0.13 & 121 & 0.15 & 108 \\
\hline Jpn World Econ & 0.17 & 94 & 0.24 & 76 & 0.05 & 167 & 0.02 & 201 & 0.15 & 111 \\
\hline Empir Econ & - & - & 0.13 & 109 & 0.13 & 112 & 0.13 & 124 & 0.15 & 111 \\
\hline J Econ Psychol & 0.38 & 70 & 0.16 & 99 & 0.17 & 99 & 0.11 & 132 & 0.15 & 111 \\
\hline J Comp Econ & 0.12 & 113 & 0.18 & 93 & 0.18 & 98 & 0.11 & 135 & 0.15 & 114 \\
\hline Int Rev Law Econ & 0.96 & 33 & 0.08 & 136 & 0.16 & 106 & 0.17 & 104 & 0.15 & 114 \\
\hline Camb J Econ & - & - & 0.12 & 117 & 0.08 & 141 & 0.06 & 167 & 0.15 & 114 \\
\hline J Prod Anal & 0.24 & 82 & 0.16 & 98 & 0.17 & 102 & 0.14 & 117 & 0.15 & 115 \\
\hline Astin Bull & - & - & 0.08 & 135 & 0.12 & 118 & 0.26 & 77 & 0.15 & 117 \\
\hline World Dev & 0.12 & 110 & 0.12 & 116 & 0.15 & 107 & 0.12 & 129 & 0.15 & 117 \\
\hline J Common Mark S & 0.08 & 122 & 0.43 & 55 & 0.35 & 67 & 0.05 & 178 & 0.14 & 118 \\
\hline Insur Math Econ & 0.40 & 66 & 0.13 & 109 & 0.13 & 117 & 0.15 & 110 & 0.14 & 119 \\
\hline J Bank Financ & 0.20 & 86 & 0.20 & 86 & 0.24 & 91 & 0.18 & 100 & 0.13 & 120 \\
\hline J Regul Econ & 0.54 & 50 & 0.09 & 127 & 0.29 & 76 & 0.45 & 60 & 0.13 & 121 \\
\hline Rev Income Wealth & 0.33 & 74 & 0.18 & 91 & 0.42 & 58 & 0.24 & 88 & 0.13 & 122 \\
\hline Energ J & 0.13 & 104 & 0.16 & 98 & 0.24 & 90 & 0.56 & 53 & 0.13 & 123 \\
\hline Stud Nonlinear Dyn E & 0.32 & 76 & 0.13 & 112 & 0.05 & 167 & 0.09 & 147 & 0.12 & 124 \\
\hline Be J Macroecon & - & - & - & - & - & - & 0.07 & 163 & 0.12 & 125 \\
\hline World Bank Res Obser & 0.13 & 107 & 0.55 & 46 & 0.26 & 84 & 0.04 & 179 & 0.12 & 126 \\
\hline Land Econ & 0.26 & 80 & 0.22 & 82 & 0.18 & 97 & 0.23 & 90 & 0.11 & 128 \\
\hline Rev Ind Organ & 0.16 & 97 & 0.36 & 63 & 0.06 & 149 & 0.22 & 92 & 0.11 & 128 \\
\hline World Econ & 0.13 & 107 & 0.14 & 107 & 0.25 & 88 & 0.17 & 103 & 0.11 & 130 \\
\hline Agr Econ-Blackwell & - & - & 0.04 & 155 & 0.09 & 138 & 0.05 & 177 & 0.11 & 130 \\
\hline Ger Econ Rev & - & - & - & - & - & - & 0.05 & 176 & 0.11 & 131 \\
\hline Pac Econ Rev & - & - & 0.02 & 166 & 0.04 & 173 & 0.03 & 193 & 0.11 & 132 \\
\hline Pharmacoeconomics & - & - & - & - & - & - & 0.03 & 190 & 0.11 & 133 \\
\hline Be J Econ Anal Poli & - & - & - & - & - & - & 0.13 & 123 & 0.11 & 134 \\
\hline J Evol Econ & 0.11 & 117 & 0.17 & 94 & 0.12 & 120 & 0.09 & 146 & 0.10 & 136 \\
\hline $\mathrm{J}$ Econ Issues & 0.01 & 155 & 0.04 & 155 & 0.03 & 175 & 0.01 & 209 & 0.10 & 136 \\
\hline Value Health & - & - & - & - & - & - & 0.01 & 205 & 0.10 & 137 \\
\hline Europe-Asia Stud & 0.02 & 151 & 0.17 & 96 & 0.00 & 188 & 0.01 & 211 & 0.09 & 138 \\
\hline Aust Econ Hist Rev & - & - & - & - & 0.66 & 42 & 0.51 & 57 & 0.09 & 140 \\
\hline Rev World Econ & 0.00 & 158 & 0.07 & 142 & 0.10 & 127 & 0.14 & 117 & 0.09 & 140 \\
\hline Environ Resour Econ & 0.19 & 88 & 0.12 & 116 & 0.12 & 119 & 0.20 & 96 & 0.09 & 142 \\
\hline Contemp Econ Policy & 0.06 & 129 & 0.12 & 113 & 0.09 & 133 & 0.15 & 112 & 0.09 & 142 \\
\hline J Inst Theor Econ & 0.19 & 88 & 0.09 & 125 & 0.26 & 85 & 0.34 & 70 & 0.08 & 143 \\
\hline Economist-Netherland & 0.06 & 132 & 0.01 & 169 & 0.06 & 152 & 0.04 & 182 & 0.08 & 146 \\
\hline Scot J Polit Econ & 0.23 & 83 & 0.10 & 123 & 0.05 & 159 & 0.13 & 122 & 0.08 & 146 \\
\hline $\mathrm{J}$ Forest Econ & - & - & 0.04 & 161 & 0.05 & 159 & 0.10 & 140 & 0.08 & 146 \\
\hline $\mathrm{J}$ Afr Econ & 0.04 & 139 & 0.05 & 152 & 0.09 & 137 & 0.12 & 128 & 0.08 & 147 \\
\hline Resour Energy Econ & 0.14 & 101 & 0.26 & 75 & 0.09 & 133 & 0.25 & 83 & 0.08 & 148 \\
\hline Cesifo Econ Stud & - & - & 0.04 & 157 & 0.05 & 167 & 0.07 & 157 & 0.08 & 149 \\
\hline Asian Econ Policy R & - & - & - & - & - & - & 0.03 & 187 & 0.07 & 150 \\
\hline J Sport Econ & - & - & - & - & - & - & 0.21 & 95 & 0.07 & 151 \\
\hline Ecol Econ & 0.04 & 141 & 0.05 & 153 & 0.06 & 149 & 0.11 & 134 & 0.07 & 152 \\
\hline Eur Rev Agric Econ & 0.03 & 146 & 0.03 & 164 & 0.06 & 153 & 0.05 & 174 & 0.07 & 153 \\
\hline J Policy Model & 0.05 & 138 & 0.08 & 133 & 0.04 & 169 & 0.09 & 152 & 0.06 & 155 \\
\hline J Dev Stud & 0.12 & 113 & 0.19 & 88 & 0.11 & 124 & 0.14 & 114 & 0.06 & 155 \\
\hline Econ Transit & 0.08 & 126 & 0.13 & 111 & 0.14 & 109 & 0.14 & 118 & 0.06 & 159 \\
\hline Kyklos & 0.07 & 127 & 0.14 & 105 & 0.12 & 121 & 0.07 & 159 & 0.06 & 159 \\
\hline Econ Rec & 0.09 & 121 & 0.06 & 144 & 0.08 & 141 & 0.10 & 136 & 0.06 & 159 \\
\hline Aust J Agr Resour Ec & 0.03 & 142 & 0.09 & 127 & 0.07 & 143 & 0.09 & 144 & 0.06 & 159 \\
\hline J Cult Econ & - & - & - & - & - & - & 0.06 & 170 & 0.06 & 161 \\
\hline
\end{tabular}


Table 2 - continued from previous page

\begin{tabular}{|c|c|c|c|c|c|c|c|c|c|c|}
\hline \multirow[b]{2}{*}{ Journal } & \multicolumn{2}{|c|}{2006} & \multicolumn{2}{|c|}{2007} & \multicolumn{2}{|c|}{2008} & \multicolumn{2}{|c|}{2009} & \multicolumn{2}{|c|}{2010} \\
\hline & $\mathrm{sc}$ & $\mathrm{r}$ & $\mathrm{sc}$ & $\mathrm{r}$ & $\mathrm{sc}$ & $\mathrm{r}$ & $\mathrm{sc}$ & $\mathrm{r}$ & $\mathrm{sc}$ & $\mathrm{r}$ \\
\hline Eur J Health Econ & - & - & - & - & - & - & 0.07 & 159 & 0.06 & 161 \\
\hline Finanzarchiv & - & - & - & - & 0.14 & 109 & 0.05 & 174 & 0.06 & 164 \\
\hline Econ Hum Biol & - & - & - & - & 0.28 & 78 & 0.10 & 140 & 0.06 & 164 \\
\hline Energ Econ & 0.18 & 93 & 0.18 & 92 & 0.05 & 162 & 0.19 & 97 & 0.06 & 164 \\
\hline J Econ & 0.39 & 68 & 0.08 & 131 & 0.25 & 86 & 0.09 & 149 & 0.06 & 167 \\
\hline Inf Econ Policy & 0.13 & 107 & 0.05 & 150 & 0.13 & 117 & 0.51 & 56 & 0.06 & 167 \\
\hline Appl Econ Lett & 0.06 & 130 & 0.07 & 139 & 0.10 & 131 & 0.10 & 142 & 0.06 & 167 \\
\hline J Real Estate Res & - & - & - & - & 0.06 & 155 & 0.09 & 152 & 0.05 & 168 \\
\hline J Agr Resour Econ & 0.04 & 140 & 0.06 & 148 & 0.06 & 145 & 0.08 & 155 & 0.05 & 171 \\
\hline Mar Resour Econ & - & - & - & - & - & - & 0.10 & 138 & 0.05 & 171 \\
\hline Hist Polit Econ & - & - & - & - & 0.04 & 170 & 0.07 & 160 & 0.05 & 171 \\
\hline J Econ Surv & 0.06 & 129 & 0.12 & 118 & 0.14 & 111 & 0.12 & 130 & 0.05 & 172 \\
\hline J Hous Econ & 0.72 & 41 & 0.06 & 146 & 0.14 & 110 & 0.05 & 174 & 0.05 & 173 \\
\hline Be J Theor Econ & - & - & - & - & - & - & 0.24 & 88 & 0.05 & 175 \\
\hline J Int Trade Econ Dev & - & - & - & - & - & - & 0.05 & 176 & 0.05 & 175 \\
\hline Food Policy & 0.03 & 144 & 0.07 & 142 & 0.06 & 147 & 0.07 & 161 & 0.05 & 176 \\
\hline J Agr Econ & 0.05 & 136 & 0.02 & 167 & 0.06 & 152 & 0.04 & 184 & 0.05 & 177 \\
\hline Manch Sch & 0.14 & 100 & 0.15 & 100 & 0.07 & 144 & 0.16 & 105 & 0.04 & 178 \\
\hline Work Employ Soc & 0.00 & 158 & 0.01 & 171 & 0.04 & 172 & 0.06 & 168 & 0.04 & 179 \\
\hline Asian Econ $\mathrm{J}$ & - & - & - & - & - & - & 0.05 & 171 & 0.04 & 181 \\
\hline Can J Agr Econ & - & - & - & - & 0.05 & 156 & 0.06 & 166 & 0.04 & 181 \\
\hline J Regional Sci & - & - & 0.14 & 104 & 0.10 & 129 & 0.14 & 119 & 0.04 & 182 \\
\hline Dev Econ & 0.01 & 156 & 0.07 & 142 & 0.02 & 181 & 0.01 & 212 & 0.04 & 183 \\
\hline Int J Transp Econ & - & - & 0.08 & 137 & 0.00 & 194 & 0.00 & 224 & 0.04 & 184 \\
\hline Open Econ Rev & 0.12 & 114 & 0.01 & 169 & 0.09 & 135 & 0.09 & 152 & 0.04 & 185 \\
\hline Econ Model & 0.10 & 118 & 0.08 & 135 & 0.05 & 168 & 0.02 & 199 & 0.03 & 187 \\
\hline Ind Corp Change & 0.17 & 95 & 0.04 & 160 & 0.13 & 113 & 0.09 & 143 & 0.03 & 187 \\
\hline S Afr J Econ & 0.06 & 134 & 0.01 & 172 & 0.04 & 171 & 0.02 & 196 & 0.03 & 188 \\
\hline Int Financ & - & - & - & - & - & - & 0.25 & 81 & 0.03 & 191 \\
\hline Jahrb Natl Stat & 0.01 & 154 & - & - & 0.02 & 180 & 0.01 & 213 & 0.03 & 191 \\
\hline Rev Int Polit Econ & 0.12 & 110 & 0.08 & 129 & 0.27 & 83 & 0.06 & 166 & 0.03 & 191 \\
\hline J Post Keynesian Ec & 0.05 & 137 & 0.06 & 145 & 0.05 & 157 & 0.04 & 186 & 0.03 & 192 \\
\hline J Media Econ & 0.00 & 162 & 0.00 & 179 & 0.00 & 188 & 0.03 & 191 & 0.03 & 194 \\
\hline China Econ Rev & 0.08 & 125 & 0.11 & 120 & 0.05 & 162 & 0.02 & 195 & 0.03 & 194 \\
\hline Econ Geogr & 0.12 & 111 & 0.05 & 152 & 0.11 & 122 & 0.03 & 192 & 0.02 & 195 \\
\hline Aust Econ Pap & - & - & - & - & - & - & 0.06 & 170 & 0.02 & 196 \\
\hline New Polit Econ & 0.03 & 149 & 0.04 & 158 & 0.05 & 162 & 0.01 & 204 & 0.02 & 197 \\
\hline Emerg Mark Financ Tr & 0.02 & 152 & 0.01 & 174 & 0.10 & 128 & 0.02 & 203 & 0.02 & 199 \\
\hline Post-Sov Aff & 0.03 & 145 & 0.14 & 106 & 0.01 & 182 & 0.01 & 210 & 0.02 & 199 \\
\hline Aust Econ Rev & - & - & - & - & 0.03 & 178 & 0.06 & 166 & 0.02 & 200 \\
\hline China World Econ & - & - & - & - & 0.00 & 189 & 0.02 & 200 & 0.02 & 202 \\
\hline Futures & 0.03 & 148 & 0.07 & 143 & 0.10 & 127 & 0.02 & 203 & 0.02 & 202 \\
\hline Eur J Hist Econ Thou & - & - & 0.03 & 164 & 0.03 & 175 & 0.32 & 71 & 0.01 & 204 \\
\hline Tijdschr Econ Soc Ge & 0.09 & 120 & 0.03 & 165 & 0.10 & 125 & 0.03 & 189 & 0.01 & 204 \\
\hline J Agrar Change & - & - & - & - & 0.05 & 167 & 0.24 & 85 & 0.01 & 206 \\
\hline J Appl Econ & - & - & 0.01 & 173 & 0.03 & 176 & 0.12 & 126 & 0.01 & 206 \\
\hline J Asia Pac Econ & - & - & - & - & - & - & 0.03 & 189 & 0.01 & 207 \\
\hline Asian-Pac Econ Lit & - & - & - & - & - & - & 0.04 & 182 & 0.01 & 210 \\
\hline Defence Peace Econ & 0.09 & 119 & 0.15 & 101 & 0.06 & 154 & 0.08 & 153 & 0.01 & 210 \\
\hline Port Econ J & - & - & 0.01 & 170 & 0.03 & 178 & 0.14 & 117 & 0.01 & 210 \\
\hline Post-Communist Econ & 0.00 & 159 & 0.03 & 162 & 0.01 & 186 & 0.02 & 199 & 0.00 & 211 \\
\hline Eastern Eur Econ & 0.03 & 143 & 0.01 & 175 & 0.02 & 180 & 0.01 & 209 & 0.00 & 213 \\
\hline Singap Econ Rev & - & - & - & - & - & - & 0.02 & 199 & 0.00 & 213 \\
\hline Cepal Rev & - & - & - & - & - & - & 0.01 & 209 & 0.00 & 224 \\
\hline
\end{tabular}


Table 2 - continued from previous page

\begin{tabular}{|r|rr|rr|rrrrr|rr|}
\hline & \multicolumn{2}{|c|}{2006} & \multicolumn{2}{|c|}{2007} & \multicolumn{2}{c|}{2008} & \multicolumn{2}{c|}{2009} & \multicolumn{2}{c|}{2010} \\
Journal & $\mathrm{sc}$ & $\mathrm{r}$ & $\mathrm{sc}$ & $\mathrm{r}$ & $\mathrm{sc}$ & $\mathrm{r}$ & $\mathrm{sc}$ & $\mathrm{r}$ & $\mathrm{sc}$ & $\mathrm{r}$ \\
\hline Ekon Cas & 0.00 & 160 & - & - & 0.00 & 194 & 0.00 & 224 & 0.00 & 224 \\
Invest Econ-Mex & - & - & - & - & - & - & 0.01 & 214 & 0.00 & 224 \\
J Bus Econ Manag & - & - & - & - & - & - & 0.00 & 224 & 0.00 & 224 \\
Polit Ekon & 0.02 & 150 & 0.00 & 179 & 0.00 & 190 & 0.00 & 224 & 0.00 & 224 \\
Rev Econ Apl-Spain & - & - & - & - & 0.06 & 152 & 0.00 & 216 & 0.00 & 224 \\
Rev Econ Mund & - & - & - & - & - & - & 0.00 & 224 & 0.00 & 224 \\
Rev Econ Polit & - & - & 0.00 & 179 & 0.00 & 194 & 0.00 & 224 & 0.00 & 224 \\
S Afr J Econ Manag S & - & - & - & - & 0.01 & 186 & 0.00 & 217 & 0.00 & 224 \\
Transform Bus Econ & - & - & - & - & - & - & 0.00 & 224 & 0.00 & 224 \\
Trimest Econ & 0.00 & 162 & 0.00 & 179 & 0.01 & 184 & 0.00 & 215 & 0.00 & 224 \\
\hline
\end{tabular}

\section{B Data Format and Source Code}

We organized the data in three types of files:

- the $m$ file - in this file, for each year $t$, there is a spreadsheet containing the citation matrix $C^{t}$ where an entry in row $i$, column $j$ is the total number of cites made in year $t$ by articles in journal $j$ to articles in journal $i$ no older than 4 years;

- the $a$ file - in this file, for each year $t$, there is a spreadsheet containing a column with the number of articles $a$ published by each journal in that year;

- the $c$ file - in this file, for each year $t$, there is a spreadsheet containing a column with the total number of citations $c_{j}$ made by journal $j$ to articles in journals in $J$ no older than 4 years.

To obtain the raw ranking vectors from the above matrices, we used the following code in Wolfram Mathematica 8.0:

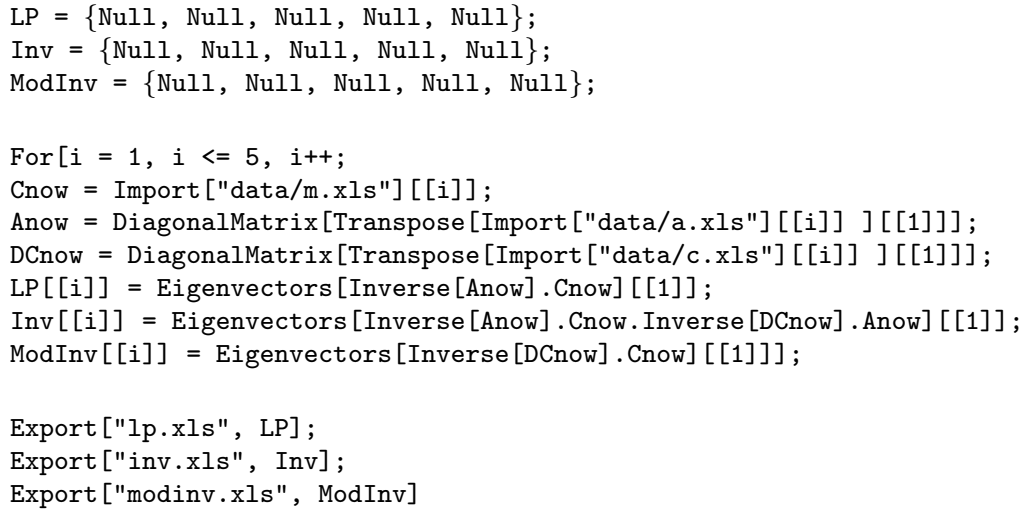

The diagonal matrices $A$ and $D_{C}$ are generated by our code from the data files. Each year we have a different set of journals: for each year the raw score vectors are copied next to the lists of journals and are normalized. The overall ranking is produced by sorting the journals according to their scores. 


\section{Detailed Calculations}

Writing Equality 7 in detail for the left most and right most terms of the equality, we obtain the following system of equations:

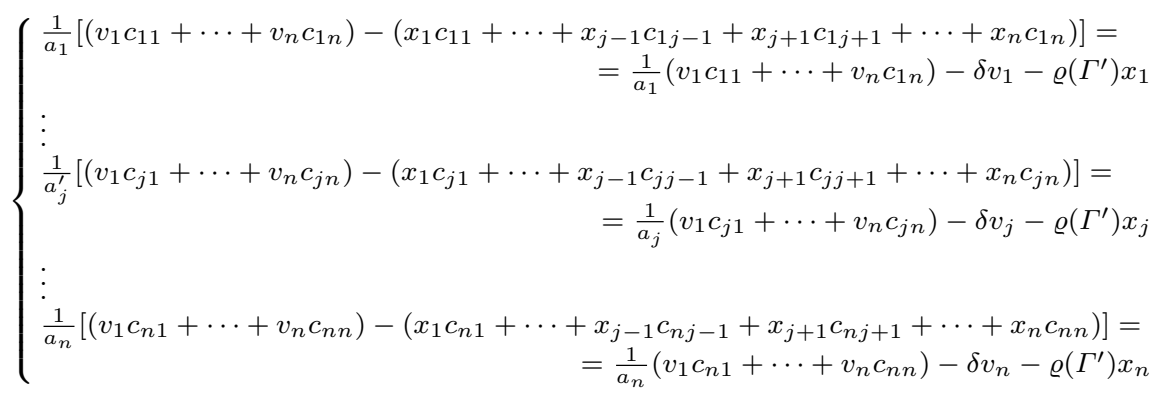

After canceling terms and dropping the $j$ 'th row from the system of equations above, we obtain:

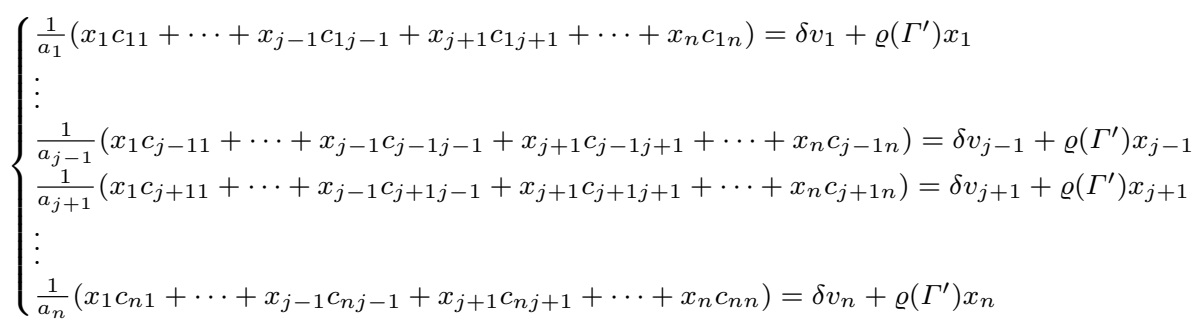

Rewriting the above system of equations using vector and matrix notation yields Equation 8 .

\section{References}

Altman A, Tennenholtz M (2005) Ranking systems: The PageRank axioms. In: Proceedings of the 6th ACM conference on Electronic commerce (EC-05), ACM, ACM Press, New York, pp 1-8

Bergstrom CT (2007) Eigenfactor: measuring the value and prestige of scholarly journals. College \& Research Libraries News 68(5):314-316

Bergstrom CT, West JD, Wiseman MA (2008) The Eigenfactor metrics. The Journal of Neuroscience 28(45):11,433-11,434

Braun T, Glänzel W, Schubert A (2006) A Hirsch-type index for journals. Scientometrics 69(1):169-173

Brin S, Page L (1998) The anatomy of a large-scale hypertextual web search engine. Computer Networks and ISDN Systems 30(1-2):107-117

Campbell DE, Kelly JS (2009) Gains from manipulating social choice rules. Economic Theory $40(3): 349-371$

Campbell DE, Kelly JS (2010) Losses due to manipulation of social choice rules. Economic Theory 45(3):453-467

Combes PP, Linnemer L (2003) Where are the economists who publish? Publication concentration and rankings in Europe based on cumulative publications. Journal of the European Economic Association 1(6):1250-1308

Coupé T (2003) Revealed performances: Worldwide rankings of economists and economics departments, 1990-2000. Journal of the European Economic Association 1(6):1309-1345

DeGroot MH (1974) Reaching a consensus. Journal of the American Statistical Association 69(345):118-121 
Garfield E (1955) Citation indexes to science: A new dimension in documentation through association of ideas. Science 122(3159):108-111

Golub B, Jackson MO (2010) Naive learning in social networks and the wisdom of crowds. American Economic Journal: Microeconomics 2(1):112-149

González-Pereira B, Guerrero-Bote VP, Moya-Anegón F (2009) The SJR indicator: A new indicator of journals' scientific prestige. Tech. Rep. 4141, ArXiv.org

Hirsch JE (2004) An index to quantify an individual's scientific research output. Proceedings of the National Academy of Sciences 102(46):16,569-16,572

Jemec GBE (2001) Impact factor to assess academic output. The Lancet 358(9290):1373

Kalaitzidakis P, Mamuneas TP, Stengos T (2003) Rankings of academic journals and institutions in economics. Journal of the European Economic Association 1(6):1346-1366

Kóczy LÁ, Strobel M (2008) The invariant method can be manipulated. Scientometrics 81(1):291-293

Kóczy LÁ, Strobel M (2010) The world cup of economics journals: A ranking by a tournament method. Iehas discussion papers, Institute of Economics, Hungarian Academy of Sciences

Laband DN, Piette MJ (1994) The relative impacts of economics journals: 1970-1990. Journal of Economic Literature 32:640-666

Langville AN, Meyer CD (2006) Google's PageRank and beyond: The science of search engine rankings. Princeton University Press, Princeton, New Jersey

Liebowitz SJ, Palmer JC (1984) Assessing the relative impacts of economics journals. Journal of Economic Literature 22(1):77-88

Marcus M, Minc M (1975) On two theorems of frobenius. Pacific Journal of Mathematics $60(2): 149-151$

Mirrlees JA, Neary PJ, Tirole J (2003) Evaluating economics research in europe: an introduction. Journal of the European Economic Association 1(6):1239-1249

Opátrný T (2008) Playing the system to give low-impact journal more clout. Nature 455(7210):167-167

Palacios-Huerta I, Volij O (2004) The measurement of intellectual influence. Econometrica $72(3): 963-977$

Pinski G, Narin F (1976) Citation influence for journal aggregates of scientific publications: Theory, with application to the literature of physics. Information Processing \& Management 12(5):297-312

Roy S, Saberi A, Wan Y (2008) Majorization for the dominant eigenvector of a nonnegative matrix. American Control Conference, Westin Seattle Hotel, Seattle, Washington, USA pp 1965-1966

Shoham Y, Leyton-Brown K (eds) (2009) Multiagent Systems. Algorithmic, GameTheoretic, and Logical Foundations. Cambridge University Press, Cambridge

Smith R (1997) Journal accused of manipulating impact factor. British Medical Journal 314(7079):461

Sobel J (2000) Economists' models of learning. Journal of Economic Theory 94(1):241-261

Zimmermann C (2007) Academic Rankings with RePEc. Department of Economics Working Paper Series 2007-36, University of Connecticut, Storrs, CT 